\title{
Prevalences of metabolic syndrome and its sex-specific association with socioeconomic status in rural China: a cross-sectional study
}

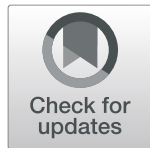

Xuhua Ying ${ }^{1+}$, Shuyue Yang ${ }^{2+}$, Songtao Li ${ }^{1}$, Meifang Su${ }^{1}$, Na Wang ${ }^{2}$, Yue Chen ${ }^{3 *}$, Qingwu Jiang ${ }^{2}$ and Chaowei $\mathrm{Fu}^{2^{*}}$ (iD)

\begin{abstract}
Background: Few studies have reported the prevalence of metabolic syndrome (MS) and examined relationships between socioeconomic status and MS in rural China. This study aimed to evaluate the prevalence of MS and MS components as well as their associations with socioeconomic status among rural Chinese adults.

Methods: A cross-sectional study of 26,836 participants aged 20 years and older was conducted from June to December 2012 in Yuhuan City, Zhejiang Province, China, which is located on Yuhuan Island. A multivariable logistic regression model was used to identify risk factors for MS and their possible interactions.

Results: Among 26,836 subjects with an average age of $53.4 \pm 14.0$ years, 59\% were female. The overall prevalence of MS was $20.5 \%$, and there was a significant sex difference in the prevalence $(15.1 \%$ for males vs. $24.2 \%$ for females, $P<0.001)$. Compared with males, females also showed a significantly higher proportion of most MS components. A significantly higher prevalence of MS was found among subjects who were elderly, had a lower income level, had a lower level of education, or were unemployed. Multiple significant interactions were observed between the prevalence of MS and sex, age or socioeconomic status $(P<0.001)$. The risk of MS increased significantly with age in females but not in males. Additionally, a lower income level and a lower level of education were significantly related to an increased risk only in females, and unemployed males had a higher risk of MS than unemployed females.

Conclusions: The prevalence of MS and its components was relatively high in a rural island Chinese population with rapid urbanization, and sex-specific associations between socioeconomic factors and MS were found. Targeted preventive interventions should be developed and implemented to prevent and control MS among those with low socioeconomic status, especially females.
\end{abstract}

Keywords: Metabolic syndrome, Socioeconomic status, Sex differences, East China

\footnotetext{
* Correspondence: ychen@uottawa.ca; fcw@fudan.edu.cn

${ }^{+}$Xuhua Ying and Shuyue Yang contributed equally to this work.

${ }^{3}$ School of Epidemiology and Public Health, Faculty of Medicine, University

of Ottawa, Ottawa, Ontario, Canada

${ }^{2}$ School of Public Health; Key Laboratory of Public Health Safety, NHC Key

Laboratory of Health Technology Assessment, Fudan University, Shanghai

200032, China

Full list of author information is available at the end of the article
}

C C The Author(s). 2021 Open Access This article is licensed under a Creative Commons Attribution 4.0 International License, which permits use, sharing, adaptation, distribution and reproduction in any medium or format, as long as you give appropriate credit to the original author(s) and the source, provide a link to the Creative Commons licence, and indicate if changes were made. The images or other third party material in this article are included in the article's Creative Commons licence, unless indicated otherwise in a credit line to the material. If material is not included in the article's Creative Commons licence and your intended use is not permitted by statutory regulation or exceeds the permitted use, you will need to obtain permission directly from the copyright holder. To view a copy of this licence, visit http://creativecommons.org/licenses/by/4.0/. The Creative Commons Public Domain Dedication waiver (http://creativecommons.org/publicdomain/zero/1.0/) applies to the data made available in this article, unless otherwise stated in a credit line to the data. 


\section{Background}

Non-communicable chronic diseases (NCDs) are a major cause of mortality and an increasing socioeconomic burden globally [1-3]. It was exacerbated by rapid economic growth, aging population, and lifestyle changes [4]. Metabolic syndrome (MS), is characterized by clustering risk factors for NCDs, including central obesity, high blood pressure, raised hyperglycemia, and low highdensity lipoprotein cholesterol [5]. The prevalence of MS has increased rapidly in both developed and developing countries and areas in recent years [6-10]. In China, this prevalence increased rapidly from $13.7 \%$ in 2005 to $33.9 \%$ in 2010 to $24.5 \%$ in 2016 [11-13]. Findings from previous studies have suggested that MS and its components are risk factors for atrial fibrillation, stroke, cardiovascular disease (CVD), diabetes mellitus (DM) and other NCDs [14, 15]. There were few studies about the status of MS and its possible influencing factors among island residents in rural China [16, 17]. Yuhuan County, located on Yuhuan Island, is one of the most developed areas in China and is experiencing rapid urbanization among rural residents; however, there is a relatively high prevalence of several chronic diseases due to high-salt and high-fat diets $[18,19]$.

Recent studies have shown that socioeconomic status (SES) is a strong predictor of morbidity and premature mortality both in developing and developed countries [20, 21]. Prior studies reported that lower SES was associated with a higher risk for NCDs such as type 2 diabetes and coronary heart disease, and the severity varied by sex $[22,23]$. With the changing socioeconomic environment, few studies have examined the association between SES and MS in rural East China [24, 25]. This study aimed to estimate the prevalence of MS and the association between SES and MS in different sexes in a rural area with rapid urbanization in East China.

\section{Methods}

\section{Study site and population}

A cross-sectional study was conducted in 3 communities in Yuhuan City, Zhejiang Province, from June to December 2012 using cluster sampling. The studied communities included 1 street, 1 town and 1 township which were randomly selected from 3 streets, 6 towns and 2 townships of Yuhuan City respectively and all members were recruited into this study with a response rate of $78.4 \%$. A total of 26,836 participants were included in this research, and the inclusion criteria were as follows: 1) 20 years and older; 2) local permanent resident without migration or travel plans (1 year or longer); 3 ) provided informed consent; and 4) able to complete the questionnaire and physical examination.

\section{Data collection and quality control}

Face-to-face questionnaire interviews were conducted and anthropometric data were collected by trained local health professionals. The following demographic information data was collected with the questionnaire (seen in Supplementary file 1): age; sex; lifestyle information, including smoking history (non-smoker/former smoker/ current smoker) [26], alcohol consumption (to drink at least once a week as yes) [27], and regular physical exercise (doing physical exercise at least 1 time a week, for at least $30 \mathrm{~min}$ each time, and feeling warm or sweaty) [28]; socioeconomic status, including years of education ( $<9$ years $/ \geq 9$ years) [26], monthly household income $(<$ $2000 \mathrm{RMB} / \geq 2000 \mathrm{RMB}$ ), and occupation status (Manual worker/ Mental/ worker/ Unemployed/ Other) [29]; and health conditions, including disease history of hypertension, diabetes mellitus, stroke, cardiovascular disease or other [30]. Anthropometry data included height, weight, waist and hip circumference, and blood pressure.

Blood samples were collected after an 8-h fast and analyzed in a reference laboratory to assess blood biochemical indexes, including fasting plasma glucose (FPG), 2-h postprandial blood glucose (2hPG), total cholesterol (TC), low-density lipoprotein cholesterol (LDL-C), highdensity lipoprotein cholesterol (HDL-C), and triglyceride (TG).

\section{Definition of metabolic syndrome}

The diagnosis of metabolic syndrome was based on IDF criteria as follows:

Central obesity (defined as waist circumference $\geq 90$ $\mathrm{cm}$ for males or $\geq 80 \mathrm{~cm}$ for females, or BMI $>30 \mathrm{~kg} / \mathrm{m}^{2}$ ) plus any two or more of four additional factors:

(1) Triglyceride levels $\geq 1.7 \mathrm{mmol} / \mathrm{L}$ (150 mg/dL);

(2) High blood pressure: systolic blood pressure $\geq 130$ $\mathrm{mmHg}$ or diastolic blood pressure $\geq 85 \mathrm{mmHg}$ or treatment of previously diagnosed hypertension;

(3) High-density lipoprotein cholesterol levels $<1.03$ $\mathrm{mmol} / \mathrm{L}(40 \mathrm{mg} / \mathrm{dL})$ in males and $1.29 \mathrm{mmol} / \mathrm{L}$ (50 $\mathrm{mg} / \mathrm{dL}$ ) in females or specific treatment for lipid abnormalities;

(4) Fasting plasma glucose levels $\geq 5.6 \mathrm{mmol} / \mathrm{L}$ (100 mg/ $\mathrm{dL}$ ) or previously diagnosed type 2 diabetes [31].

\section{Statistical analysis}

All data were entered into Epidata 3.1 twice. Pearson's chi-square test or Fisher's exact test was applied for categorical variables. Student's t-test or the Wilcoxon test was used for two-group comparisons of normally distributed and nonnormally distributed continuous variables, respectively. Logistic regression analysis was used to calculate crude odds ratios (cORs), adjusted ORs (aORs), and $95 \%$ confidential intervals (CIs) to estimate the 
potential risk factors as well as to explore the possible interactions between sex and socioeconomic factors. All analyses were conducted using SPSS 22.0, and a twosided $P$-value of 0.05 or less was defined as significant, missing data were deleted.

\section{Results}

Basic characteristics of subjects (Table 1)

Data from 26,836 individuals were analyzed, including $59 \%$ females with an average age of $53.4 \pm 14.0$ years.
Compared with male subjects, females were more likely to have lower levels of education, lower monthly household income levels, and unemployment. Males showed significantly higher proportions of smoking and alcohol consumption. Additionally, MS components, including hypertension, high FPG levels and high TG levels, were more common in males than in females, except for the low level of HDL-C. In addition, BMI and waist circumference were significantly higher in males than in females.

Table 1 Characteristics of subjects over sex in the rural Chinese population

\begin{tabular}{|c|c|c|c|c|}
\hline Characteristics & $\begin{array}{l}\text { Male, }(\%) \\
(n=10,998)\end{array}$ & $\begin{array}{l}\text { Female, }(\%) \\
(n=15,838)\end{array}$ & Total, (\%) & $P$ value $^{\mathrm{e}}$ \\
\hline Age group (years) & & & & 0.013 \\
\hline$<40$ & 18.5 & 17.7 & 17.8 & \\
\hline $40-$ & 23.5 & 24.9 & 24.3 & \\
\hline $50-$ & 23.8 & 24.2 & 24.1 & \\
\hline $60-$ & 21.3 & 20.7 & 21.0 & \\
\hline$\geq 70$ & 13.4 & 12.4 & 12.8 & \\
\hline Education year ( $\geq 9)$ & 12.4 & 10.8 & 11.5 & $<0.001$ \\
\hline Occupation status ${ }^{a}$ & & & & $<0.001$ \\
\hline Manual worker & 32.7 & 18.2 & 24.1 & \\
\hline Mental worker & 14.8 & 8.1 & 10.9 & \\
\hline Unemployed & 28.4 & 62.5 & 48.5 & \\
\hline Others & 24.0 & 11.2 & 16.5 & \\
\hline Regular physical exercise (Yes) ${ }^{b}$ & 43.5 & 56.1 & 50.8 & $<0.001$ \\
\hline Monthly household income & & & & $<0.001$ \\
\hline$<2000$ RMB & 36.7 & 49.2 & 44.1 & \\
\hline$\geq 2000 \mathrm{RMB}$ & 63.3 & 50.8 & 55.9 & \\
\hline Smoking & & & & $<0.001$ \\
\hline Non-smoker & 52.9 & 99.5 & 80.4 & \\
\hline Former smoker & 4.1 & 0.3 & 1.9 & \\
\hline Current smoker & 43.0 & 0.2 & 17.7 & \\
\hline Alcohol consumption (Yes) & 38.7 & 0.3 & 16.0 & $<0.001$ \\
\hline Hypertension (Yes) ${ }^{c}$ & 59.2 & 49.2 & 53.3 & $<0.001$ \\
\hline Diabetes mellitus (Yes) & 7.8 & 7.4 & 7.6 & $<0.001$ \\
\hline $\mathrm{FPG}(>5.6 \mathrm{mmol} / \mathrm{L})^{\mathrm{d}}$ & 28.3 & 23.6 & 25.5 & $<0.001$ \\
\hline $\mathrm{TG}(\geq 1.7 \mathrm{mmol} / \mathrm{L})$ & 33.3 & 23.5 & 27.5 & $<0.001$ \\
\hline $\mathrm{HDL}-\mathrm{C}(<1.03 \mathrm{mmol} / \mathrm{L})$ & 8.3 & 25.2 & 18.2 & $<0.001$ \\
\hline Age (years) (Mean \pm SD) & $53.6 \pm 14.3$ & $53.3 \pm 13.8$ & $53.4 \pm 14.0$ & 0.142 \\
\hline $\mathrm{SBP},(\mathrm{mmHg}),($ Mean $\pm \mathrm{SD})$ & $133.7 \pm 18.9$ & $129.9 \pm 21.2$ & $131.4 \pm 20.3$ & $<0.001$ \\
\hline DBP, $(m m H g),($ Mean $\pm S D)$ & $79.4 \pm 11.7$ & $75.4 \pm 10.9$ & $77.0 \pm 11.4$ & $<0.001$ \\
\hline $\mathrm{BMI},(\mathrm{kg} / \mathrm{m} 2),($ Mean $\pm \mathrm{SD})$ & $24.1 \pm 3.8$ & $23.6 \pm 3.7$ & $23.8 \pm 3.8$ & $<0.001$ \\
\hline WC, $(\mathrm{cm}),($ Mean $\pm S D)$ & $83.0 \pm 9.4$ & $78.5 \pm 9.6$ & $80.3 \pm 9.8$ & $<0.001$ \\
\hline WHR (Mean \pm SD) & $0.90 \pm 0.08$ & $0.86 \pm 0.09$ & $0.88 \pm 0.09$ & $<0.001$ \\
\hline
\end{tabular}

Notes: FPG Fasting plasma glucose, TG Triglyceride, HDL-C High-density lipoprotein cholesterol, SBP Systolic blood pressure, DBP Diastolic blood pressure, BMI Body mass index, WC Waist circumference, WHR Waist-to-hip ratio; ${ }^{\mathrm{a}}: 54$ data loss; ${ }^{\mathrm{b}}: 2484$ data loss; ${ }^{c}: 7$ data loss; ${ }^{\mathrm{d}}: 52$ data loss. ${ }^{\mathrm{e}}:$ t or chi-square test 
Table 2 Prevalence and possible risk factors of subjects for metabolic syndrome

\begin{tabular}{|c|c|c|c|c|c|}
\hline Characteristics & $\begin{array}{l}\text { Non-MS, (\%) } \\
(n=20,908)\end{array}$ & $\begin{array}{l}\text { MS, (\%) } \\
(n=5396)^{a}\end{array}$ & $P$ value $^{d}$ & Crude OR $(95 \% \mathrm{Cl})$ & 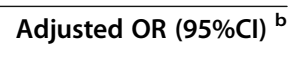 \\
\hline Sex & & & $<0.001$ & & \\
\hline Male & 84.9 & 15.1 & & 1.00 & 1.00 \\
\hline Female & 75.8 & 24.2 & & $1.79(1.68,1.91)$ & $1.98(1.79,2.18)$ \\
\hline Age group (years) & & & $<0.001$ & & \\
\hline$<40$ & 93.1 & 6.9 & & 1.00 & 1.00 \\
\hline $40-$ & 85.6 & 14.4 & & $2.29(2.00,2.62)$ & $2.22(1.91,2.57)$ \\
\hline $50-$ & 77.0 & 23.0 & & $4.05(3.57,4.60)$ & $3.80(3.29,4.39)$ \\
\hline $60-$ & 70.3 & 29.7 & & $5.74(5.05,6.52)$ & $5.40(4.64,6.28)$ \\
\hline$\geq 70$ & 68.7 & 31.3 & & $6.19(5.41,7.09)$ & $5.86(4.97,6.90)$ \\
\hline P-interaction ${ }^{c}$ & & & & & $<0.001$ \\
\hline Monthly household income & & & $<0.001$ & & \\
\hline$\geq 2000 \mathrm{RMB}$ & 83.7 & 16.3 & & 1.00 & 1.00 \\
\hline$<2000 \mathrm{RMB}$ & 74.1 & 25.9 & & $1.80(1.70,1.91)$ & $1.07(0.99,1.15)$ \\
\hline P-interaction ${ }^{c}$ & & & & & $<0.001$ \\
\hline Education year & & & $<0.001$ & & \\
\hline$\geq 9$ & 89.2 & 10.8 & & 1.00 & 1.00 \\
\hline$<9$ & 78.2 & 21.8 & & $2.29(2.03,2.58)$ & $1.19(1.04,1.37)$ \\
\hline P-interaction ${ }^{c}$ & & & & & $<0.001$ \\
\hline Occupation status & & & $<0.001$ & & \\
\hline Manual worker & 86.7 & 13.3 & & 1.00 & 1.00 \\
\hline Mental worker & 84.7 & 15.3 & & $1.18(1.04,1.33)$ & $1.64(1.43,1.89)$ \\
\hline Unemployed & 73.2 & 26.8 & & $2.38(2.19,2.58)$ & $1.43(1.30,1.58)$ \\
\hline Others & 84.0 & 16.0 & & $1.24(1.11,1.38)$ & $1.33(1.18,1.50)$ \\
\hline P-interaction ${ }^{c}$ & & & & & $<0.001$ \\
\hline Smoking & & & $<0.001$ & & \\
\hline Non-smoker & 78.3 & 21.7 & & 1.00 & 1.00 \\
\hline Former smoker & 85.1 & 14.9 & & $0.63(0.49,0.81)$ & $0.91(0.69,1.19)$ \\
\hline Current smoker & 84.3 & 15.7 & & $0.67(0.62,0.73)$ & $1.15(1.02,1.29)$ \\
\hline P-interaction ${ }^{c}$ & & & & & 0.205 \\
\hline Alcohol consumption & & & $<0.001$ & & \\
\hline No & 78.8 & 21.2 & & 1.00 & 1.00 \\
\hline Yes & 83.3 & 16.7 & & $0.74(0.68,0.81)$ & $1.28(1.14,1.45)$ \\
\hline$P$-interaction ${ }^{c}$ & & & & & 0.533 \\
\hline
\end{tabular}

Notes: ${ }^{\text {a }}$ : 532 data loss. ${ }^{\text {b}}$ : Adjusted for sex, age group, monthly household income, education year, occupation status, regular physical exercise, smoking, alcohol consumption; ${ }^{c}$ : Interactions between sex and socioeconomic factors, including age group, monthly household income, education year, unemployed. ${ }^{\text {: }}$

Chi-square test

Prevalence of MS and its influencing factors (Tables 2 \& 3 ) The overall prevalence of MS was $20.1 \%$, and there was a significant sex difference in the prevalence between males and females $(15.0 \%$ vs. $24.2 \%, p<0.001)$. Additionally, participants who were elderly or unemployed, or had a lower monthly household income, or had a lower level of education, had a significantly higher prevalence of MS, and after the adjustment for covariates, there were significant interactions between sex and SES $(P<0.001)$.
Males who were mental workers or unemployed had a higher risk of MS, and females with a lower monthly household income, lower education level, and unemployment had a higher risk of MS.

\section{Sex-specific prevalence of MS components (Table 4)}

The prevalence of MS components (except HDL-C) among females increased with age, but only the prevalence of hypertension among males increased with age. 
Table 3 Different risk-factors of subjects by sex for metabolic syndrome

\begin{tabular}{|c|c|c|c|c|c|}
\hline \multirow[t]{2}{*}{ Characteristics } & \multirow[t]{2}{*}{ OR $(95 \% \mathrm{CI})^{\mathrm{a}}$} & \multicolumn{2}{|c|}{ Male $(n=10,998)$} & \multicolumn{2}{|c|}{ Female $(n=15,838)$} \\
\hline & & MS, (\%) ${ }^{b}$ & Adjusted OR $(95 \% \mathrm{Cl})$ & $\overline{M S},(\%)^{c}$ & Adjusted OR (95\%Cl) \\
\hline \multicolumn{6}{|c|}{ Monthly household income } \\
\hline$\geq 2000$ RMB & 1.00 & 15.3 & 1.00 & 17.1 & 1.00 \\
\hline$<2000 \mathrm{RMB}$ & $2.48(2.15,2.87)$ & 14.9 & $0.83(0.73,0.95)$ & 31.6 & $1.20(1.10,1.32)$ \\
\hline \multicolumn{6}{|l|}{ Education year } \\
\hline$\geq 9$ & 1.00 & 13.8 & 1.00 & 8.4 & 1.00 \\
\hline$<9$ & $3.48(2.67,4.53)$ & 15.3 & $0.90(0.75,1.09)$ & 26.1 & $1.56(1.27,1.93)$ \\
\hline \multicolumn{6}{|l|}{ Occupation status } \\
\hline Manual worker & 1.00 & 11.5 & 1.00 & 15.6 & 1.00 \\
\hline Mental worker & $0.44(0.33,0.58)$ & 17.1 & $1.70(1.42,2.04)$ & 13.1 & $1.17(0.94,1.46)$ \\
\hline Unemployed & $1.28(1.05,1.56)$ & 17.9 & $1.70(1.45,2.00)$ & 29.5 & $1.20(1.05,1.38)$ \\
\hline Others & $0.69(0.54,0.88)$ & 15.7 & $1.37(1.16,1.61)$ & 16.4 & $1.08(0.89,1.31)$ \\
\hline
\end{tabular}

Notes: Adjusted for age group, monthly household income, education year, occupation status, smoking, alcohol consumption, regular physical exercise. ${ }^{a}$ : This column represents the OR $(95 \% \mathrm{Cl})$ for the interaction; ${ }^{b}: 255$ data loss; ${ }^{c}: 277$ data loss

It was revealed that females had higher prevalences of most MS components, especially HDL-C, than males in all age groups, whereas there were higher proportions of triglyceride levels, high blood pressure, and FPG levels among males under the age of 70 (Supplementary file 2: Supplementary Fig. 1). As presented in Table 4, females had a higher risk of HDL-C and central obesity components, while males had higher triglyceride levels, higher blood pressure, and higher FPG levels after the adjustment for demographic and other MS components.

\section{Discussion}

In this study, we found a high prevalence of MS of 20.1\% among 26,836 participants in Yuhuan County, a coastal area located in developed East China, which was similar to previous studies ranging from 22.0 to $25.3 \%$, and a higher prevalence for females was observed, which was consistent with previous studies [15, 32, 33]. Compared with the Northwest or other developing areas in China, MS was more prevalent in East China [34, 35]. The prevalence of MS increased with age in females, while in males, it first increased and then decreased, which was similar to the findings of other studies [36].
Furthermore, the prevalence in females was higher than that in males among individuals over the age of 50 years old and among those over the age of 60 years old, which may be associated with menopausal estrogen deficiency $[37,38]$.

The following shuld be merged into the above paragraph, which is a comment and should be removed. Another explanation was that the sex hormones affecting skeletal muscle mass were decreased in elderly and female subjects, which resulted in lower muscle mass and a higher risk of NCDs [39, 40]. Such an increase for women may also result from similar age-related trends in all MS components except HDL-C (Supplementary file 2: Supplementary Fig. 1).

Another finding of this study was that significant interactions on MS between sex and SES were observed among individuals. In this study, females with a lower SES (especially lower income and lower education level) showed a higher risk for MS, which was consistent with prior studies [41-44]. This finding could be explained by the following potential reasons. On one hand, participants with a lower SES were more likely to be exposed to unhealthy behaviors, psychological distress, lower life

Table 4 Associations between sex and metabolic syndrome components among subjects

\begin{tabular}{|c|c|c|c|c|}
\hline MS components & Crude OR $(95 \% \mathrm{Cl})$ & $P$ value & Adjusted OR $(95 \% \mathrm{Cl})$ & $P$ value \\
\hline Raised triglycerides ${ }^{a}$ & $0.61(0.58,0.65)$ & $<0.001$ & $0.45(0.41,0.49)$ & $<0.001$ \\
\hline High blood pressure ${ }^{b}$ & $0.67(0.64,0.70)$ & $<0.001$ & $0.57(0.52,0.62)$ & $<0.001$ \\
\hline High FPG ${ }^{c}$ & $0.79(0.75,0.83)$ & $<0.001$ & $0.72(0.66,0.78)$ & $<0.001$ \\
\hline Low HDL-C ${ }^{d}$ & $3.74(3.46,4.04)$ & $<0.001$ & $4.57(4.01,5.22)$ & $<0.001$ \\
\hline Central obesity ${ }^{e}$ & $2.48(2.35,2.62)$ & $<0.001$ & $2.87(2.63,3.13)$ & $<0.001$ \\
\hline
\end{tabular}

Notes: Male were taken as the reference group. Fixed covariates: age, education level, monthly household income, occupation status, regular physical exercise, smoking, alcohol drinking; ${ }^{a}$ : Adjusted for fixed covariates + BMI, HBP, HDL-C, FPG, Central obesity; ${ }^{\text {b }}$ : Adjusted for fixed covariates + BMI, TG, HDL-C, FPG, Central

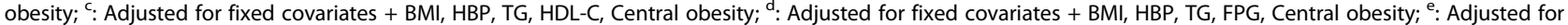
fixed covariates+ HBP, TG, HDL-C, FPG 
expectancy, lower access to health care, lower awareness of disease prevention and control, and a series of NCDs, such as obesity, hypertension, and diabetes mellites, which are commonly associated with MS [21, 41-43]. In another hand, compared with females, lower income was shown to be a protective factor for MS among males, which may be due to males being more likely to have a manual occupation with reduced risk for MS [44, 45]. Nam's study reported that office workers had a higher risk of MS than manual workers, which was consistent with the present study [46].

\section{Limitations and strengths}

This study was carried out in the rural Chinese community population with rapid urbanization, and the findings should be helpful to understand the status of MS in other similar areas of China or other countries. Of course, some limitations should be discussed. First, this study population was from Zhejiang Province, one of the developed areas in China, where the socioeconomic and lifestyle factors may be different than those in other rural areas in China. For example, the per capita Gross domestic product (GDP) of Yuhuan was 88,421 RMB in 2012, which was higher than the average level of China $[47,48]$. Second, anthropometric and demographic information was collected at a single point, which may lead to data inaccuracy, and it was less feasible for the present study to only use IDF criteria as a definition without using other new definitions. Third, as a crosssectional study, it is not possible to draw causal conclusions. Fourth, demographic information was selfreported and collected by questionnaires, which may lead to report bias. Fifth, male and female may come from the same family and share the same monthly household income number which could bias the findings. In addition, it was noted that some potential confounders such as diet factors were not controlled in this study. A prospective cohort study should be conducted in the future to confirm the causal association between SES factors and the incident of MS, especially regarding sex differences.

\section{Conclusions}

Our study indicated the different distribution of MS prevalence and MS components in males and females as well as sex differences in the association between SES and MS. This study also updated the prevalence data in the Yuhuan rural area in Zhejiang Province in China. Risk factors for MS were identified to provide a reference for the prevention and management of this disease. More interventions and policies regarding the risk factors for MS need to be applied for people with lower SES, especially in females, to increase access to health care and to reduce health inequalities.

\section{Abbreviations}

MS: Metabolic syndrome; IDF: International Diabetes Federation; ORs: Odds ratios; Cls: 95\% confidence intervals; BMI: Body mass index; NCDs: Noncommunicable chronic disease; SES: Socioeconomic status; AF: Atrial fibrillation; CVD: Cardiovascular disease; DM: Diabetes mellitus; FPG: Fasting plasma glucose; 2hPG: 2-h postprandial blood glucose; TC: Total cholesterol; LDL-C: Low-density lipoprotein cholesterol; HDL-C: High-density lipoprotein cholesterol; TG: Triglyceride; SBP: Systolic blood pressure; DBP: Diastolic blood pressure; HBP: High blood pressure

\section{Supplementary Information}

The online version contains supplementary material available at https://doi. org/10.1186/s12889-021-12074-z.

Additional file 1: Supplementary file 1. Baseline Questionnaire of Yuhuan Population Health Cohort Study.

Additional file 2: Supplementary file 2. Supplementary Figure 1. Prevalence of metabolic syndrome and its components in different age groups over sex. Notes: TG: Triglyceride; BP: Blood pressure; FPG: Fasting plasma glucose; HDL-C: High-density lipoprotein cholesterol, A: Total; B: Male group; C: Female group.

\section{Acknowledgements \\ We gratefully acknowledge all the staff who participated in this project, including health workers in Yuhuan City Center for Disease Control and Prevention, from the Fudan School of Public Health, and from local community-based health facilities.}

\section{Authors' contributions}

XHY and SYY analysed the data, interpreted the analysis results and drafted the manuscript. YC, QJ and CF designed the study and revised the

manuscript. XHY, STL, MFS and NW analysed the data and collected the data. MFS, STL and XHY collected data and supervised the study. All authors read and approved the final manuscript.

\section{Funding}

This work was supported by the National Natural Science Foundation of China (grant number 81473038) and Taizhou City Science Program (grant number 1401KY49). The sponsors had no role in the study design, survey process, data analysis or manuscript preparation.

\section{Availability of data and materials}

The datasets generated and/or analysed during the current study are not publicly available owing to local legislation and the written consent forms of participants but are available from the corresponding author on reasonable request.

\section{Declarations}

Ethics approval and consent to participate

The Institutional Review Board of the Fudan University School of Public Health approved this study, and all participants gave written informed consent.

Consent for publication

Not applicable.

Competing interests

The authors have no conflicts of interest to declare.

\section{Author details}

${ }^{1}$ Yuhuan City Center for Disease Control and Prevention, Yuhuan, Zhejiang Province, China. ${ }^{2}$ School of Public Health; Key Laboratory of Public Health Safety, NHC Key Laboratory of Health Technology Assessment, Fudan University, Shanghai 200032, China. ${ }^{3}$ School of Epidemiology and Public Health, Faculty of Medicine, University of Ottawa, Ottawa, Ontario, Canada. 


\section{Received: 29 September 2020 Accepted: 21 October 2021} Published online: 06 November 2021

\section{References}

1. He Y, Jiang B, Wang J, Feng K, Chang Q, Fan L, et al. Prevalence of the metabolic syndrome and its relation to cardiovascular disease in an elderly Chinese population. J Am Coll Cardiol. 2006;47(8):1588-94. https://doi.org/1 0.1016/j.jacc.2005.11.074

2. Patrick W, Sullivan VG, Wyatt HR, Hill JO. The Medical Cost of Cardiometabolic Risk Factor Clusters in the United States. Obesity. 2007; 15(12):3150-8. https://doi.org/10.1038/oby.2007.375.

3. Dagenais GR, Leong DP, Rangarajan S, Lanas F, Lopez-Jaramillo P, Gupta R, et al. Variations in common diseases, hospital admissions, and deaths in middle-aged adults in 21 countries from five continents (PURE): a prospective cohort study. Lancet. 2020;395(10226):785-94. https://doi.org/1 0.1016/S0140-6736(19)32007-0

4. Cai L, He J, Song Y, Zhao K, Cui W. Association of obesity with socioeconomic factors and obesity-related chronic diseases in rural southwest China. Public Health. 2013;127(3):247-51. https://doi.org/10.1016/j.puhe.2 012.12.027.

5. Robert H, Eckel KGMMA, Grundy SM, Zimmet PZ. The metabolic syndrome Lancet. 2010;375(9710):181-3. https://doi.org/10.1016/S0140-6736(09)61 794-3.

6. Sostaric A, Jenko B, Kozjek NR, Ovijac D, Suput D, Milisav I, et al. Detection of metabolic syndrome burden in healthy young adults may enable timely introduction of disease prevention. Arch Med Sci. 2019:15(5):1184-94. https://doi.org/10.5114/aoms.2019.87462.

7. Estes C, Anstee QM, Arias-Loste MT, Bantel H, Bellentani S, Caballeria J, et al. Modeling NAFLD disease burden in China, France, Germany, Italy, Japan, Spain, United Kingdom, and United States for the period 2016-2030. J Hepatol. 2018;69(4):896-904. https://doi.org/10.1016/j.jhep.2018.05.036

8. Lim S, Shin H, Song JH, Kwak SH, Kang SM, Won Yoon J, et al. Increasing prevalence of metabolic syndrome in Korea: the Korean National Health and Nutrition Examination Survey for 1998-2007. Diabetes Care. 2011;34(6): 1323-8. https://doi.org/10.2337/dc10-2109.

9. Kaduka LU, Kombe Y, Kenya E, Kuria E, Bore JK, Bukania ZN, et al. Prevalence of metabolic syndrome among an urban population in Kenya. Diabetes Care. 2012;35(4):887-93. https://doi.org/10.2337/dc11-0537.

10. Maria Aguilar TB, Torres S, Liu B, Wong RJ. Prevalence of the Metabolic Syndrome in the United States, 2003-2012. JAMA. 2015;313(19):1973-4. https://doi.org/10.1001/jama.2015.4260.

11. Gu D, Reynolds K, Wu X, Chen J, Duan X, Reynolds RF, et al. Prevalence of the metabolic syndrome and overweight among adults in China. Lancet. 2005;365(9468):1398-405. https://doi.org/10.1016/S0140-6736(05)66375-1.

12. Li R, Li W, Lun Z, Zhang H, Sun Z, Kanu JS, et al. Prevalence of metabolic syndrome in Mainland China: a meta-analysis of published studies. BMC Public Health. 2016;16(1):296. https://doi.org/10.1186/s12889-016-2870-y.

13. Lu J, Wang L, Li M, Xu Y, Jiang Y, Wang W, et al. Metabolic Syndrome Among Adults in China: The 2010 China Noncommunicable Disease Surveillance. J Clin Endocrinol Metab. 2017;102(2):507-15. https://doi.org/1 0.1210/jc.2016-2477.

14. Gu L, Xie J, Long J, Chen Q, Chen Q, Pan R, et al. Epidemiology of major depressive disorder in mainland china: a systematic review. PLoS One. 2013; 8(6):e65356. https://doi.org/10.1371/journal.pone.0065356.

15. Cheng L, Yan W, Zhu L, Chen Y, Liu J, Xu Y, et al. Comparative analysis of IDF, ATPIII and CDS in the diagnosis of metabolic syndrome among adult inhabitants in Jiangxi Province, China. PLoS One. 2017;12(12):e0189046. https://doi.org/10.1371/journal.pone.0189046.

16. Guo H, Gao X, Ma R, Liu J, Ding Y, Zhang M, et al. Prevalence of Metabolic Syndrome and its Associated Factors among Multi-ethnic Adults in Rural Areas in Xinjiang, China. Sci Rep. 2017;7(1):17643. https://doi.org/10.1038/s41 598-017-17870-5.

17. Xiao J, Shen C, Chu MJ, Gao YX, Xu GF, Huang JP, et al. Physical Activity and Sedentary Behavior Associated with Components of Metabolic Syndrome among People in Rural China. PLoS One. 2016;11(1):e0147062. https://doi. org/10.1371/journal.pone.0147062.

18. Su MF, Tian N, Li ST, Ying XH, Fu CW, Jiang QW. Prevalence of Hyperglycemia and Related Factors Among Rural Adults Aged 35 Years Old and Above in Yuhuan County, Zhejiang Province. Wei Sheng Yan Jiu. 2014; 43(6):890-4
19. Su MF, Chen XY, Xiao T, Li ST, Ying XH, Jiang QW, et al. Related factors for early-onset type 2 diabetes mellitus of rural adults in Yuhuan County of Zhejiang Province in 2012. Wei Sheng Yan Jiu. 2017;46(5):749-54.

20. Silvia Stringhini SS, Shipley M, Brunner E, Nabi H, Kivimaki M, Singh-Manoux A. Association of Socioeconomic Position With Health Behaviors and Mortality. JAMA. 2010;303(12):1159-66. https://doi.org/10.1001/jama.2010.2 97.

21. Stringhini S, Carmeli C, Jokela M, Avendaño M, Muennig P, Guida F, et al. Socioeconomic status and the $25 \times 25$ risk factors as determinants of premature mortality: a multicohort study and meta-analysis of 1.7 million men and women. Lancet. 2017;389(10075):1229-37. https://doi.org/10.1016/ S0140-6736(16)32380-7.

22. Shin D, Kim JM, Tandi TE, Park EC. Impact of change in job status on mortality for newly onset type II diabetes patients: 7 years follow-up using cohort data of National Health Insurance, Korea. Diabetes Metab Syndr. 2016;10(1 Suppl 1):S1-6. https://doi.org/10.1016/j.dsx.2015.08.012.

23. Zhu KF, Wang YM, Zhu JZ, Zhou QY, Wang NF. National prevalence of coronary heart disease and its relationship with human development index: A systematic review. Eur J Prev Cardiol. 2016;23(5):530-43. https://doi.org/1 $0.1177 / 2047487315587402$

24. Popkin BM. Synthesis and implications: China's nutrition transition in the context of changes across other low- and middle-income countries. Obes Rev. 2014;15(Suppl 1):60-7. https://doi.org/10.1111/obr.12120.

25. Zhai FY, Du SF, Wang ZH, Zhang JG, Du WW, Popkin BM. Dynamics of the Chinese diet and the role of urbanicity, 1991-2011. Obes Rev. 2014;15(Suppl 1):16-26. https://doi.org/10.1111/obr.12124.

26. Dong $X$, Wang $Y$, Chen $Y$, Wang $X$, Zhu J, Wang N, et al. Poor sleep quality and influencing factors among rural adults in Deqing, China. Sleep Breath. 2018;22(4):1213-20. https://doi.org/10.1007/s11325-018-1685-8.

27. Bellos S, Skapinakis P, Rai D, Zitko P, Araya R, Lewis G, et al. Longitudinal association between different levels of alcohol consumption and a new onset of depression and generalized anxiety disorder: Results from an international study in primary care. Psychiatry Res. 2016;243:30-4. https:// doi.org/10.1016/j.psychres.2016.05.049.

28. Nelson ME, Rejeski WJ, Blair SN, Duncan PW, Judge JO, King AC, et al. Physical activity and public health in older adults: recommendation from the American College of Sports Medicine and the American Heart Association. Med Sci Sports Exerc. 2007;39(8):1435-45. https://doi.org/10.124 9/mss.0b013e3180616aa2.

29. International Standard Classification of Occupations (ISCO) [https://ilostat.ilo. org/resources/concepts-and-definitions/classification-occupation/].

30. Su M, Chen X, Chen Y, Wang C, Li S, Ying X, et al. UCP2 and UCP3 variants and gene-environment interaction associated with prediabetes and T2DM in a rural population: a case control study in China. BMC Med Genet. 2018; 19(1):43. https://doi.org/10.1186/s12881-018-0554-4.

31. Federation ID. The IDF consensus worldwide definition of the metabolic syndrome; 2006. p. 1-23.

32. Zhang WH, Xue P, Yao MY, Chang HM, Wu Y, Zhang L. Prevalence of metabolic syndrome and its relationship with physical activity in suburban Beijing, China. Ann Nutr Metab. 2013;63(4):298-304. https://doi.org/10.1159/ 000355575.

33. Huang J, Huang JLW, Withers M, Chien K-L, Trihandini I, Elcarte E, et al. Prevalence of metabolic syndrome in Chinese women and men: a systematic review and meta-analysis of data from 734511 individuals. Lancet. 2018;392:S14. https://doi.org/10.1016/S0140-6736(18)32643-6.

34. Yi Z, Jing J, Xiu-ying L, Hongxia X, Jianjun Y, Yuhong Z. Prevalence of the metabolic syndrome among rural original adults in NingXia, China. BMC Public Health. 2010;10(1):140. https://doi.org/10.1186/1471-2458-10-140.

35. Zhao Y, Yan H, Yang R, Li Q, Dang S, Wang Y. Prevalence and determinants of metabolic syndrome among adults in a rural area of Northwest China. PLoS One. 2014;9(3):e91578. https://doi.org/10.1371/journal.pone.0091578.

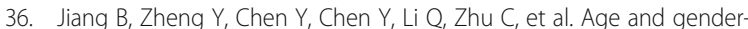
specific distribution of metabolic syndrome components in East China: role of hypertriglyceridemia in the SPECT-China study. Lipids Health Dis. 2018; 17(1):92. https://doi.org/10.1186/s12944-018-0747-z.

37. Ebtekar F, Dalvand S, Gheshlagh RG. The prevalence of metabolic syndrome in postmenopausal women: A systematic review and meta-analysis in Iran. Diabetes Metab Syndr. 2018;12(6):955-60. https://doi.org/10.1016/j.dsx.2018. 06.002 .

38. Yan HM, Zhang M, Zhang X, Xia YT, Shen T, Zhao ZP, et al. Study of epidemiological characteristics of metabolic syndrome and influencing 
factors in elderly people in China. Zhonghua Liu Xing Bing Xue Za Zhi. 2019;40(3):284-9.

39. Kupelian V, Hayes FJ, Link CL, Rosen R, McKinlay JB. Inverse association of testosterone and the metabolic syndrome in men is consistent across race and ethnic groups. J Clin Endocrinol Metab. 2008;93(9):3403-10. https://doi. org/10.1210/jc.2008-0054.

40. Ou YC, Chuang HH, Li WC, Tzeng IS, Chen JY. Gender difference in the association between lower muscle mass and metabolic syndrome independent of insulin resistance in a middle-aged and elderly Taiwanese population. Arch Gerontol Geriatr. 2017;72:12-8. https://doi.org/10.1016/j.a rchger.2017.04.006

41. Wu HF, Tam T, Jin L, Lao XQ, Chung RY, Su XF, et al. Age, gender, and socioeconomic gradients in metabolic syndrome: biomarker evidence from a large sample in Taiwan, 2005-2013. Ann Epidemiol. 2017;27(5):315-22 e312. https://doi.org/10.1016/j.annepidem.2017.04.003.

42. Linander I, Hammarstrom A, Johansson K. Which socio-economic measures are associated with psychological distress for men and women? A cohort analysis. Eur J Pub Health. 2015;25(2):231-6. https://doi.org/10.1093/eurpub/ cku137.

43. Yang F, Qian D, Liu X, Healthy A, Development Study Group in Nanjing Medical U, Data Mining Group of Biomedical Big Data in Nanjing Medical U. Socioeconomic disparities in prevalence, awareness, treatment, and control of hypertension over the life course in China. Int J Equity Health. 2017;16(1): 100. https://doi.org/10.1186/s12939-017-0597-8.

44. Park HS, Oh SW, Cho SI, Choi WH, Kim YS. The metabolic syndrome and associated lifestyle factors among South Korean adults. Int J Epidemiol. 2004;33(2):328-36. https://doi.org/10.1093/ije/dyh032.

45. Lavie CJ, Ozemek C, Carbone S, Katzmarzyk PT, Blair SN. Sedentary Behavior, Exercise, and Cardiovascular Health. Circ Res. 2019;124(5):799-815. https:// doi.org/10.1161/CIRCRESAHA.118.312669.

46. Nam JY, Kim J, Cho KH, Choi Y, Choi J, Shin J, et al. Associations of sitting time and occupation with metabolic syndrome in South Korean adults: a cross-sectional study. BMC Public Health. 2016;16(1):943. https://doi.org/1 0.1186/s12889-016-3617-5.

47. Statistical Report on National Economic and Social Development of Yuhuan in 2012 [http://www.yuhuan.gov.cn/art/2013/3/12/art_1229302012_3157378. html].

48. Statistical Report on National Economic and Social Development in 2012 [https://data.stats.gov.cn/easyquery.htm? cn=C01\&zb=A0201\&sj=2012].

\section{Publisher's Note}

Springer Nature remains neutral with regard to jurisdictional claims in published maps and institutional affiliations.

Ready to submit your research? Choose BMC and benefit from:

- fast, convenient online submission

- thorough peer review by experienced researchers in your field

- rapid publication on acceptance

- support for research data, including large and complex data types

- gold Open Access which fosters wider collaboration and increased citations

- maximum visibility for your research: over $100 \mathrm{M}$ website views per year

At BMC, research is always in progress.

Learn more biomedcentral.com/submissions 